Article

\title{
HKUST-1 Supported on Zirconium Phosphate as an Efficient Catalyst for Solvent Free Oxidation of Cyclohexene: DFT Study
}

\author{
Razia Aman ${ }^{1,2}$, Abraham Clearfield ${ }^{1}$, Mohammad Sadiq ${ }^{2, *(1)}$ and Zahid Ali ${ }^{3}$ \\ 1 Department of Chemistry, Texas A\&M University, College Station, TX 77843, USA; \\ razia.aman@yahoo.com (R.A.); clearfield@chem.tamu.edu (A.C.) \\ 2 Department of Chemistry, University of Malakand, Chakdara 18800, KP, Pakistan \\ 3 Center for Computational Materials Science, University of Malakand, Chakdara 18800, KP, Pakistan; \\ zahidf82@gmail.com \\ * Correspondence: sadiq@uom.edu.pk; Tel.: +92-945-763441
}

Received: 15 October 2018; Accepted: 5 November 2018; Published: 15 November 2018

\begin{abstract}
Layer by layer metal-organic framework (MOF) supported on zirconium phosphate (ZrP) was synthesized at very mild conditions and used for the liquid phase oxidation of cyclohexene in solvent free condition in the presence of molecular oxygen. The MOF-ZrP was characterized by $\mathrm{X}$-ray diffractometer (XRD), scanning electron microscope (SEM), thermal gravimetric analyzer (TGA), Fourier-transform infrared spectrometer (FT-IR) and Brunauer-Emmett-Teller (BET) surface area analyzer. The characterization shows a smooth morphology of MOF-ZrP with good stability under $200{ }^{\circ} \mathrm{C}$ having surface area $285 \mathrm{~m}^{2} / \mathrm{g}$. The catalytic activity of the MOF-ZrP revealed that increase of layers of MOF on $\mathrm{ZrP}$ enhances conversion, as well as selectivity of oxidation of cyclohexene. DFT studies were used to explore the structure and electron properties of HKUST-1 (Hong Kong University of Science and Technology), which is a clue for the catalytic behavior of the catalyst.
\end{abstract}

Keywords: MOF-ZrP; cyclohexene; solvent free

\section{Introduction}

Oxyfunctionalization of hydrocarbons is a fundamental reaction in organic chemistry and industry. The oxygenated products of hydrocarbons are key intermediates in valued fine chemicals. Especially six-carbon cyclic hydrocarbons, represented by cyclohexane and cyclohexene, give a variety of oxygen-containing products [1]. Hydrocarbons are naturally abundant raw feedstock for petrochemical industries, that occur in reduced form and oxidation is the only way to convert these substances into valued chemicals [2]. For this purpose, a variety of catalysts and oxidants have been utilized to convert HCs into other products, but the oxidation of these substances is not selective. Cyclohexane produces cyclohexanol and cyclohexanone, but these products are more reactive than cyclohexane and oxidize into other products [3]. Similarly, cyclohexene can be oxidized to give allylic oxidation products, such as cyclohexanol and cyclohexanone and can be oxidized at $\mathrm{C}=\mathrm{C}$ bond to give cyclohexene oxide and other products. Thus, it is still a challenge to enhance the selectivity towards ketone products by designing an efficient catalyst [4]. Many homogeneous catalysts containing redox transition metals like $\mathrm{Cu}, \mathrm{Co}, \mathrm{Fe}$ and $\mathrm{Mn}$ can oxidize alkenes with oxygen, but the catalyst separation is difficult in liquid phase reactions. To make the recovery of catalysts easy, homogeneous catalysts are anchored onto solid supports [5]. Heterogeneous catalysts with different dangerous, expensive and explosive oxidants have been reported for oxidation of HCs, that are not acceptable for industries. Therefore, the search for an ecofriendly, cheap and efficient catalytic system with molecular oxygen is never ending. Recently, metal-organic frameworks containing transition metals like $\mathrm{Cu}, \mathrm{Co}, \mathrm{Fe}, \mathrm{V}$, etc., have been reported as 
efficient catalysts in oxidation reactions [6]. Liu et al. [7] has reported $\mathrm{Cu}^{2+} @$ Comoc-4 for oxidation of cyclohexene with molecular oxygen. Three major products cyclohexenol, cyclohexenone and cyclohexene oxide were obtained with $49 \%$ conversion in $7 \mathrm{~h}$. PVMo/Hmont has been reported for allylic oxidation with hydrogen peroxide. Cyclohexene oxide, cyclohexenol, cyclohexenone and cyclohexanol were produced where the conversion was 98\% [8]. Junghans et al. [9] has reported Copper-MOF (metal-organic framework) with triazolyl isopthalate linkers for oxidation of cyclohexene where the three major products were obtained with tertiary butyl hydroperoxide (TBHP) after $7 \mathrm{~h}$. Farzaneh et al. [10] reported Mn-MOF with benzenetricarboxylate (BTC) and dimethylfurane (DMF) for oxidation of different alkanes and alkenes in the presence of TBHP. For cyclohexene, only two products, cyclohexenol and cyclohexenone were obtained. Cyclohexenone was the major product with $75 \%$ selectivity while total conversion was $100 \%$ in $24 \mathrm{~h}$. HKUST-1 has been used as catalyst for oxidation of trans-ferulic acid to vanillin. After one hour of reaction, the yield of vanillin was $98 \%$ in acetonitrile [11]. Copper immobilized within Zr-based MOF with pyridine units $\left(\mathrm{Zr}-\mathrm{MOF}-\mathrm{bpy}-\mathrm{CuBr}_{2}\right)$ has been reported as an efficient catalyst for liquid phase epoxidation of cyclooctene in toluene. The \%conversion was $88.5 \%$ with selectivity of $95.3 \%$ when TBHP was used as oxidant after $12 \mathrm{~h}$ at $363 \mathrm{~K}$ [12]. $\mathrm{Fe}_{3} \mathrm{O}_{4} @ H K U S T-1$ has been reported for one-pot sequential deacetalization and Knoevenagel condensation reaction. Benzaldehyde dimethylacetal was completely converted into benzylidenemalononitrile through the formation of benzaldehyde in $5 \mathrm{~h}$ at $363 \mathrm{~K}$ in the presence of 1,4-dioxane. Similarly, $\mathrm{Pd} / \mathrm{Fe}_{3} \mathrm{O}_{4} @ \mathrm{HKUST}-1$ has been used for hydrogenation of 1-octene with $98 \%$ yield of octane within $3 \mathrm{~h}$ [13]. Copper incorporated into $\mathrm{Zr}$-based MOF (UiO-66-(COOH $\left.)_{2}\right)$ has been reported for oxidation of cyclooctene. Three different salts of copper were utilized for catalysts preparation and tested for their catalytic activity. All the catalysts showed excellent catalytic activity yielding $99 \%$ in $4 \mathrm{~h}$ at $40{ }^{\circ} \mathrm{C}$ [14].

Layered zirconium phosphates are very attractive for materials chemists. The layered structure consists of zirconium atoms lying in a plane and sandwiched by $\mathrm{O}_{3} \mathrm{P}-\mathrm{OH}$ groups situated alternatively above and below the plane. The compound is highly insoluble in strong acidic and alkaline media [15]. Clearfield and Stynes crystallize zirconium phosphate and other Group(IV) metals for the first time in 1964. The general formula for the phosphates is $\mathrm{Zr}\left(\mathrm{HPO}_{4}\right)_{2} \cdot \mathrm{H}_{2} \mathrm{O}$ that possess layered structure. There are different methods for preparation of zirconium phosphate, but very common methods are reflux and direct precipitation. Crystallinity changes with the concentration of acid and reflux time while surface area and surface acidity decrease with increase in concentration of acid and reflux time [16]. Zirconium phosphate is a versatile ion exchanger. Each zirconium atom possesses two protons that can be exchanged by inorganic and organic cations. Clearfield et al. has interesting reports where they have studied the ion exchange behavior of $\alpha-\mathrm{ZrP}$ for $\mathrm{Na}^{+}, \mathrm{K}^{+}$and many more metal ions [17].

$\alpha-\mathrm{ZrP}$ has been investigated as an acid catalyst and catalyst support for variety of reactions. Zhang et al. reported $\alpha$-ZrP catalyst for synthesis of stearic acid monoethanolamide where conversion was $92.9 \%$ after $12 \mathrm{~h}$ of reaction at $120{ }^{\circ} \mathrm{C}$ [18]. Clearfield et al. have reported $\mathrm{Ag} / \alpha-\mathrm{ZrP}$ catalyst for oxidation of ethylene. The $\alpha-\mathrm{ZrP}$ used as support was first exchanged by $\mathrm{Na}^{+}$and $\mathrm{K}^{+}$ions, where $\mathrm{Na}^{+}$exchanged $\alpha$-ZrP proved much higher catalytic activity as compared to $\mathrm{K}^{+}$exchanged $\alpha$-ZrP [19]. Ebatani et al. investigated a composite catalyst of Pd NPs $/ \alpha-Z r P$ for the synthesis of 1,6-Hexandiol [20]. Panda et al. have investigated $\mathrm{Cr}$ (III) ions $/ \mathrm{m}-\mathrm{ZrP}$ for oxidation of allylic and benzylic compounds to corresponding carbonyl compounds. The catalyst resulted in higher conversions with $100 \%$ selectivity [21]. $\alpha$-ZrP has also been reported as solid support for organo metallic complexes. Fe(Salen) complexes and $\mathrm{Cu}$ (Salen) complexes supported on $\alpha-\mathrm{ZrP}$ have been reported for oxidation of cyclohexene with peroxides. The catalyst was prepared by a two-step method. $\mathrm{Fe}(\mathrm{III})$ and $\mathrm{Cu}$ (II) ions were exchanged in $\alpha$ - $\mathrm{ZrP}$ to form $\alpha$-ZrP-Fe(III) and $\alpha-\mathrm{ZrP}-\mathrm{Cu}$ (II) precursors. Then intercalation of salen into precursors was carried out by flexible ligand technique. The \%conversion of cyclohexene was $18.04 \%$ and $26.71 \%$ respectively, where products were cyclohexenol, cyclohexenone and cyclohexene oxide [22,23]. 
A problem with MOFs is their low thermal and chemical stability and separation from the reaction mixture. So immobilizing MOFs on the surface of support material is of great interest to make it heterogeneous especially for catalysis.

Herein we report the catalytic activity of HKUST-1 supported on zirconium phosphate in the liquid phase oxidation of cyclohexene in solvent free conditions with molecular oxygen.

\section{Results and Discussion}

The X-ray diffractometer (XRD) reveals that there is a distinct peak at $10.75^{\circ}$ for $\mathrm{ZrP}$. The progressive development of MOF layers on the surface of $\mathrm{ZrP}$ gave rise to many new peaks. With four layers of MOF deposition, the peak at $10.75^{\circ}$ disappears, which indicates the successive growth of MOF on the surface, as shown in Figure 1a-f. The characteristic peak of ZrP did not shift with the deposition of MOF suggesting that the $\mathrm{Cu}$ ions have exchanged only the surface protons and sodium ions from $\mathrm{Na}-\mathrm{ZrP}$. In order to prevent the penetration of $\mathrm{Cu}$ ions into the inter layers of zirconium phosphate, sodium exchanged $\mathrm{ZrP}$ was used as support. There is a distinct peak for MOF at $8.0^{\circ}$ with six layers of deposition. Figure 1a-f, shows the microstructure of ZrP and HKUST-1 on the surface of ZrP. With the increase in the layers of HKUST-1, the grain size gradually increased. Initially, a lower concentration of reactants resulted in the formation of a layer of minor HKUST-1 dispersed uniformly over the surface of ZrP. The smooth morphology of HKUST-1/ZrP revealed the retention of shape of parent support material and uniformed growth of HKUST-1on the surface of ZrP [24].

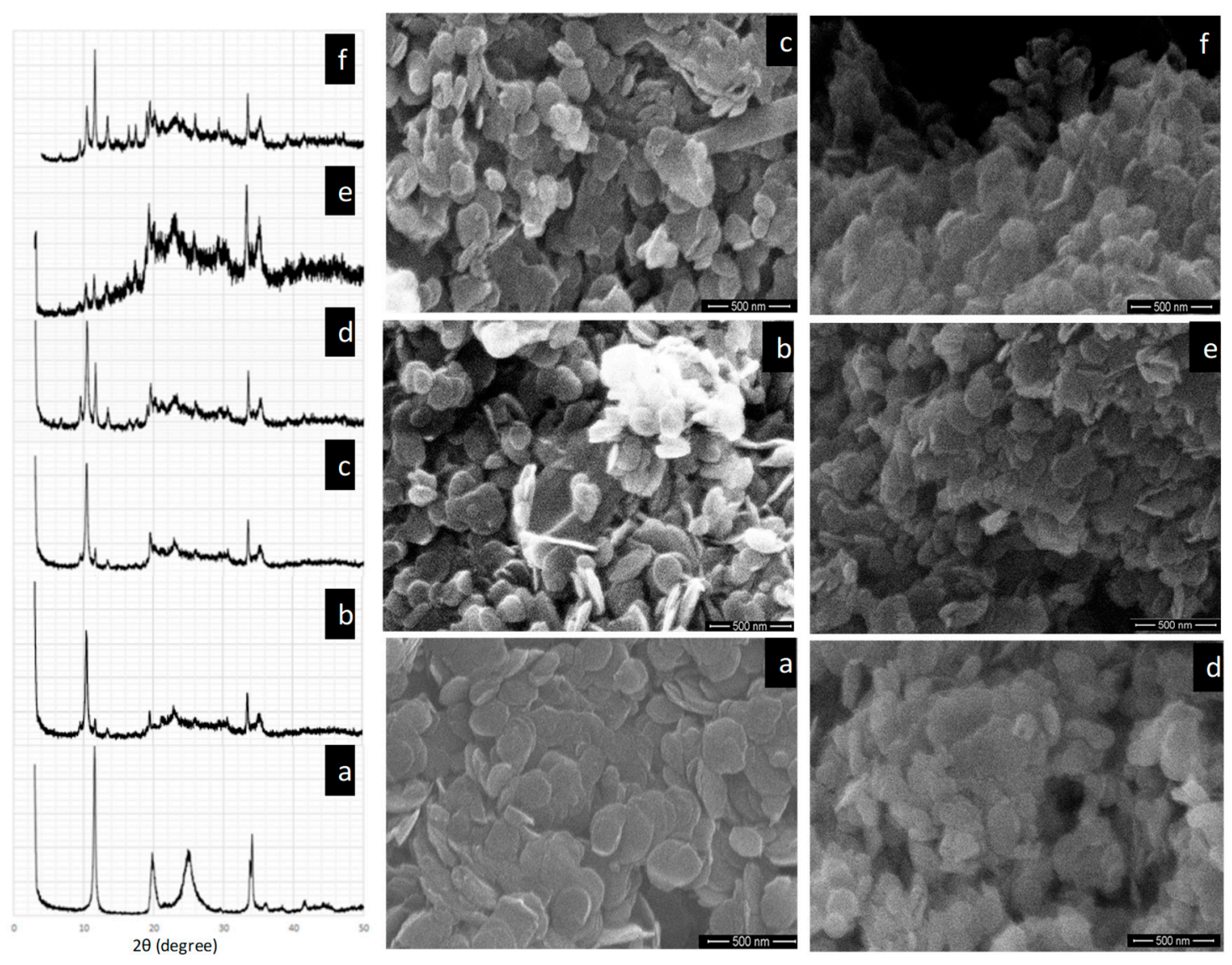

Figure 1. (a) X-ray diffractometer (XRD) pattern and scanning electron microscope (SEM) image of ZrP. (b) XRD pattern and SEM image of metal-organic framework (MOF)-ZrP with two layers. (c) XRD pattern and SEM image of MOF-ZrP with four layers. (d) XRD pattern and SEM image of MOF-ZrP with six layers. (e) XRD pattern and SEM image of MOF-ZrP with eight layers. (f) XRD pattern and SEM image of MOF-ZrP with 10 layers. 
TGA curve reveals $12 \%$ weight loss with increase in temperature, as shown in Figure 2a. The first weight loss is due to dehydration of the $\mathrm{ZrP}$ and residual solvent up to $150{ }^{\circ} \mathrm{C}$. The second weight loss beyond $150{ }^{\circ} \mathrm{C}$ to $450^{\circ} \mathrm{C}$ is due to the decomposition of ligand. Figure $2 \mathrm{~b}$ exhibits that two bands at $3595 \mathrm{~cm}^{-1}$ and $3502 \mathrm{~cm}^{-1}$ are attributed to O-H stretching. The bands at $1624 \mathrm{~cm}^{-1}$ and $1215 \mathrm{~cm}^{-1}$ are due to the carboxylate group of BTC ligand. The band at $952 \mathrm{~cm}^{-1}$ suggests the condensation of P-OH of $\mathrm{ZrP}$. The band at $609 \mathrm{~cm}^{-1}$ is due to the vibrations of $\mathrm{Zr}-\mathrm{O}$.


Figure 2. (a) TGA curves of ZrP and MOF-ZrP (a,b). (b) FTIR of MOF-ZrP. (c) BET surface area of ZrP and MOF-ZrP with different layers. (d) Pore Volume of $\mathrm{ZrP}$ and MOF-ZrP with different layers.

Figure 2c shows the surface area of $\mathrm{ZrP}$ and $\mathrm{ZrP}$ with different MOF layers. The surface area of support material that is $\mathrm{ZrP}$ is $35 \mathrm{~m}^{2} / \mathrm{g}$. After deposition of two layers of MOF, the pores of $\mathrm{ZrP}$ are covered by MOF so the surface area is reduced to $23.75 \mathrm{~m}^{2} / \mathrm{g}$ as shown in Figure 2d. Further deposition of MOF layers resulted in increase in surface area from $71.62 \mathrm{~m}^{2} / \mathrm{g}$ for MOF-ZrP with 4 layers to $285 \mathrm{~m}^{2} / \mathrm{g}$ for MOF-ZrP with 10 layers.

\subsection{DFT Study of HKUST-1}

The cell structure of HKUST-1, shown in Figure 3, was used to study the chemical bonding and electronic properties. The calculations for the chemical bonding and electronic properties of the HKUST-1 have been performed using full potential linearized augmented plan waves (FPLAPW) methods [25] in the frame work of DFT using WEIN2K code [26]. The exchange-correlation energies for all the systems are treated by generalized gradient approximation (GGA-sol) [27]. In FPLAPW technique the unit cell is separated in to two regions, the interstitial regions and the muffin-tin spheres region taking the muffin-tin radii (RMT) such that no charge leakages occur. Inside the muffin-tin spheres the wave function is expended in the spherical harmonics by taking $l_{\max }=10$ the maximum value of angular momentum and the magnitude of the largest vector in the charge density Fourier expansion is $\mathrm{G}_{\max }=12 \mathrm{Ry}^{1 / 2}$. Whereas outside the sphere (interstitial region) it is expanded in plane 
wave basis and cut-off value of $K_{\max }=6 / R_{M T}$ is taken. The convergence is ensured for less than $1 \mathrm{mRy} /$ a.u. and $1000 \mathrm{k}$-points is used in the irreducible part of the Brillouin zone.

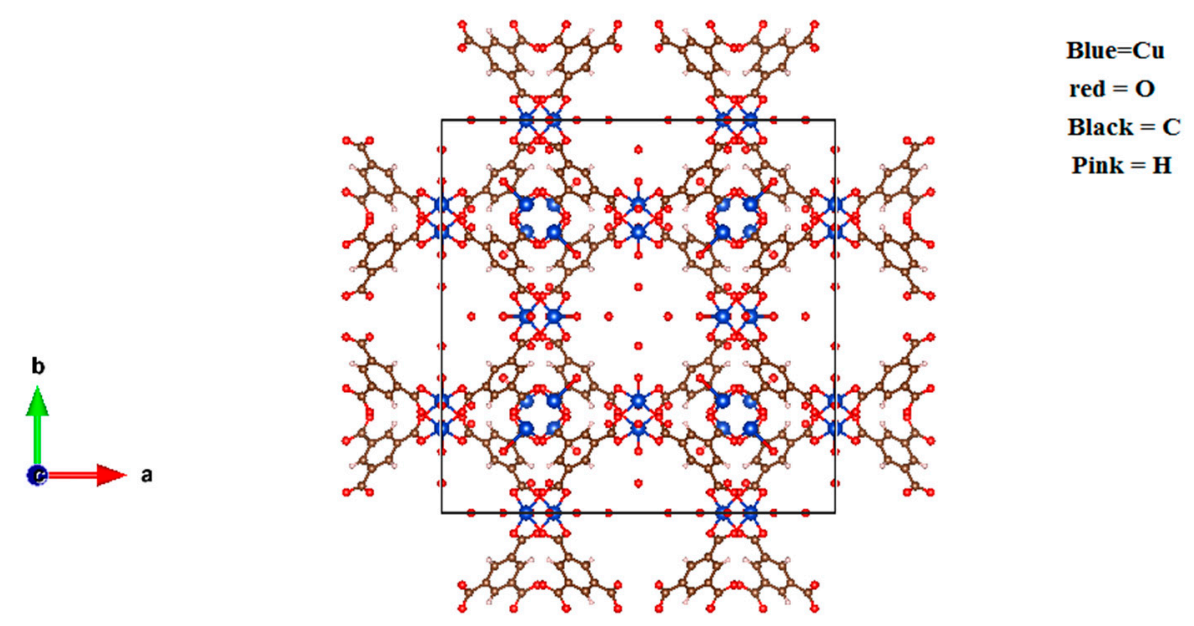

Figure 3. Structure of HKUST-1.

Chemical bonding between the constituent elements in HKUST-1 is visualized through electron charge density for the (100) and (110) crystallographic plane, as shown in Figure 4. The figure shows that there is a covalent bond between the $\mathrm{Cu}$ and $\mathrm{O}$, due to overlapping of charge densities in both (100) and (110) plane. The charge density of OW is spherical, which confirms the ionic bond between OW and $\mathrm{Cu}$ atom in the (100) plane while the bond between $\mathrm{C}$ and $\mathrm{H}$ atom is also covalent, shown in the (110) plane. On the other hand, electro-negativity of the $\mathrm{H}, \mathrm{C}, \mathrm{O}$ and $\mathrm{Cu}$ are 2.20, 2.55, 3.44 and 1.90 (Puling scale) [28,29] respectively whose electronegative difference is 0.35 and 1.54 less than 1.67 [30] also confirms covalent bond between $\mathrm{C}-\mathrm{H}$ and $\mathrm{Cu}-\mathrm{O}$.

Most of the physical properties of a compound are either directly or indirectly related with the electronic band structures. Different compounds have different kinds of band structures, due to which every compound has unique electronic properties. The electronic band structure dispersion in K-space along the high symmetry direction in the irreducible Brillouin Zone, are calculated using self-consistent field (SCF) calculations and plotted in Figure 5. The figure shows that the valance band maxima is pulled by the conduction band minima to cross the Fermi level makes the material metallic. This metallicity in the materials is due to the hybridization between $\mathrm{Cu}$ via $\mathrm{O}$ and covalent bond between $\mathrm{H}-\mathrm{C}$ as in $\mathrm{SrFeO}_{3}$ : $\mathrm{Co}$ [30]. 


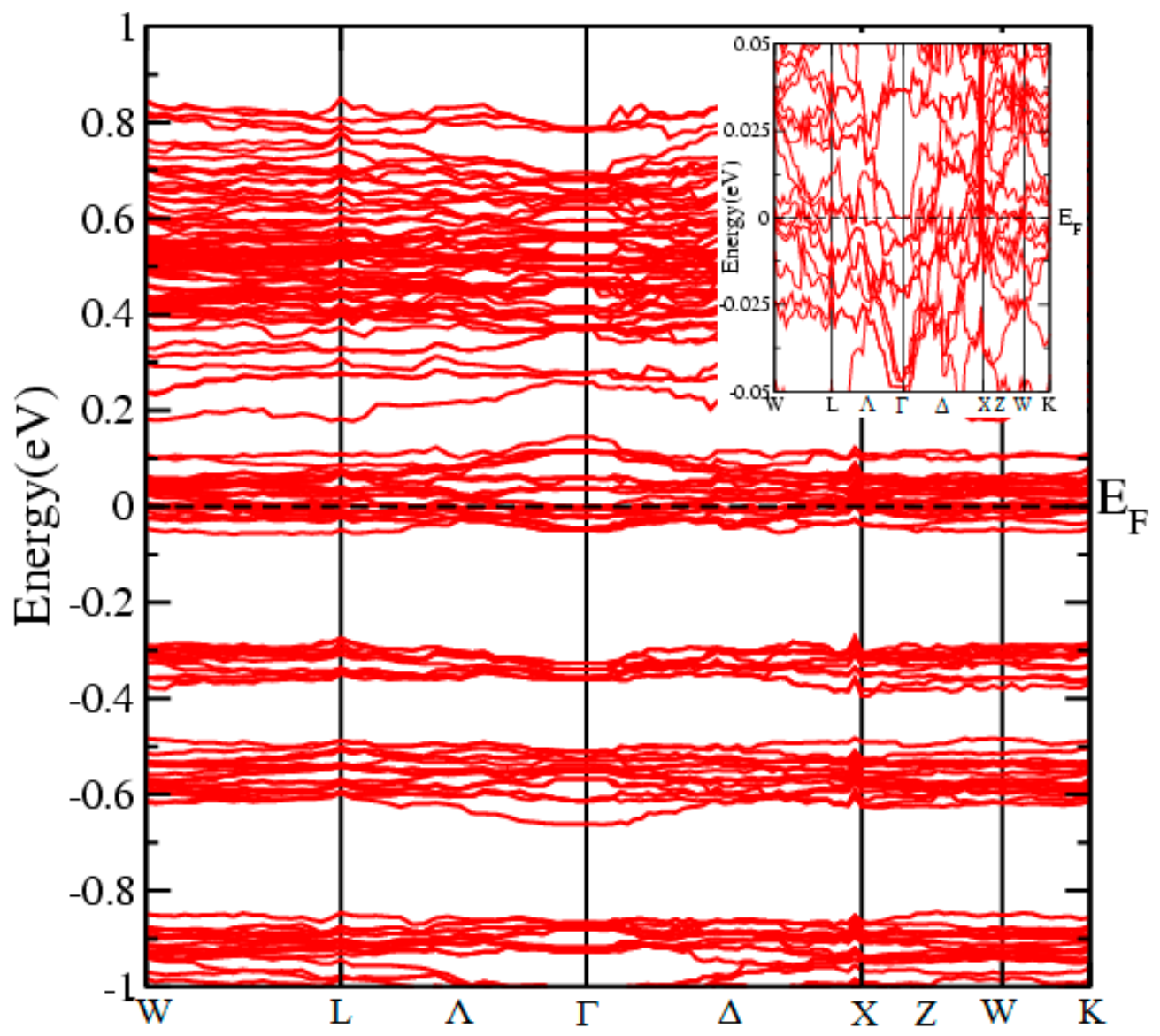

Figure 4. Electronic band structure of the HKUST-1.

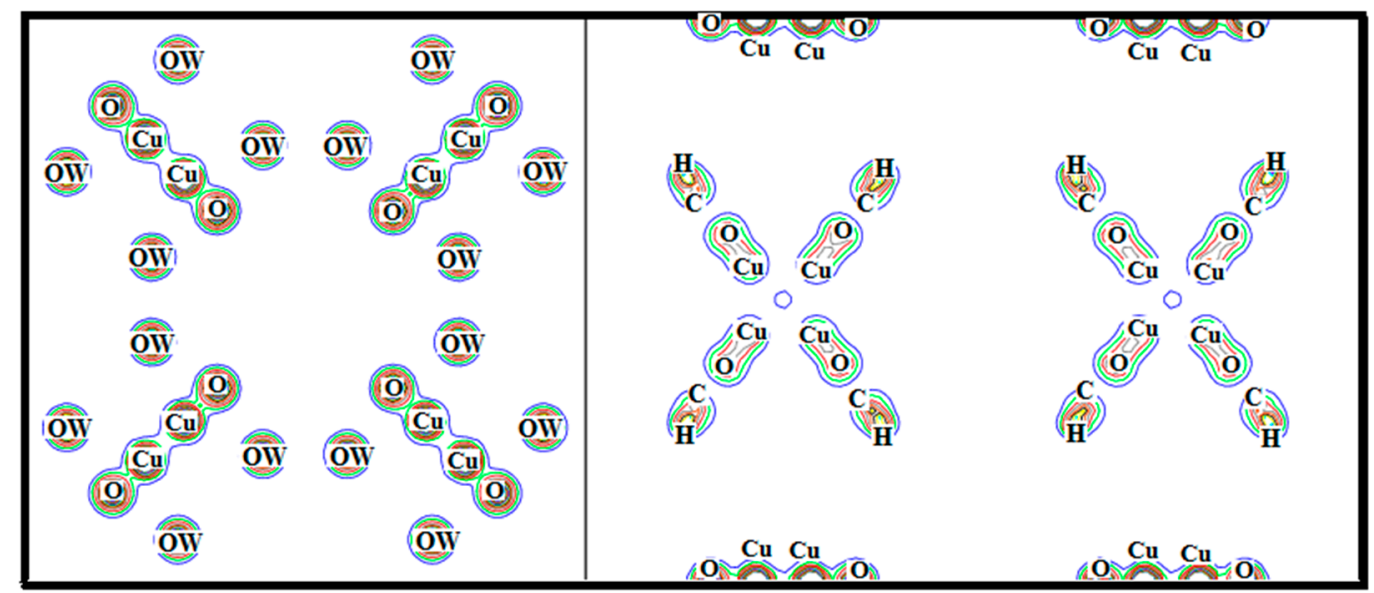

Figure 5. Electron charge densities of the HKUST-1 in (100) and in (110) crystallographic directions.

\subsection{Oxidation of Cyclohexene}

Figure 6 shows the product distribution and \% conversion as the function of different number of layers of MOF-ZrP under the experimental conditions: $10 \mathrm{~mL}$ cyclohexene with $100 \mathrm{mg}$ of catalyst at $80^{\circ} \mathrm{C}$ in $24 \mathrm{~h}$ under oxygen atmosphere. Aerobic oxidation of cyclohexene in solvent free condition yielded 2-cyclohexene-1-ol and 2-cyclohexene-1-one and also cyclohexene oxide while other minor products, such as cyclohexene dimer, cyclohexanol and cyclohexanone were also detected as reported elsewhere for $\mathrm{Cu}$ catalysts [2,31]. Cyclohexene oxide formation is a minor reaction resulting from oxidation of $\mathrm{C}=\mathrm{C}$ bond while the allylic oxidation product, 2-cyclohexen-1-one, was dominant in all 
the reactions. The selectivity towards cyclohexanone was $53.6 \%, 44.5 \%, 64.9 \%, 35.8 \%$ and $47.9 \%$ with 2, 4, 6, 8 and 10 layers of MOF-ZrP, respectively. Similarly, the selectivity towards cyclohexanol was $41.1 \%, 39.1 \%, 32.9 \%, 35.3 \%$ and $41.6 \%$ respectively. In our case the high $\%$ conversion $(93.7 \%$ and 93.6\%) was observed with 2 and 6 layers of MOF-ZrP. Although the product distribution shows much fluctuation with the layers of MOF. Figure 6 reflects that the selectivity of catalysts towards major products with ten layers of MOF was higher as compared to others where only $0.7 \%$ by-products were formed. Selectivity is very difficult for oxidation of cyclohexene, due to the existence of two active sites, the allylic $\mathrm{C}-\mathrm{H}$ bond and $\mathrm{C}=\mathrm{C}$ bond. When $\mathrm{C}=\mathrm{C}$ bond is oxidized, cyclohexene oxide, cyclohexanol, cyclohexanone and cyclohexanediol will be produced. As the $\mathrm{C}-\mathrm{H}$ bond is oxidized, 2-cyclohexene-1-ol, 2-cyclohexene-1-one and cyclohexene hydroperoxide will be formed [3]. It was observed that the abstraction of allylic hydrogen to give allylic oxidation products is more favorable with $\mathrm{Cu}-\mathrm{MOF}$ catalyst as compared to the oxidation of $\mathrm{C}=\mathrm{C}$ bond as reported elsewhere [4]. No doubt, MOF-ZrP proved excellent catalytic activity for cyclohexene oxidation, but we did not observed any catalytic activity for oxidation of cyclohexane and cycloheptane at the same set of reaction parameters.

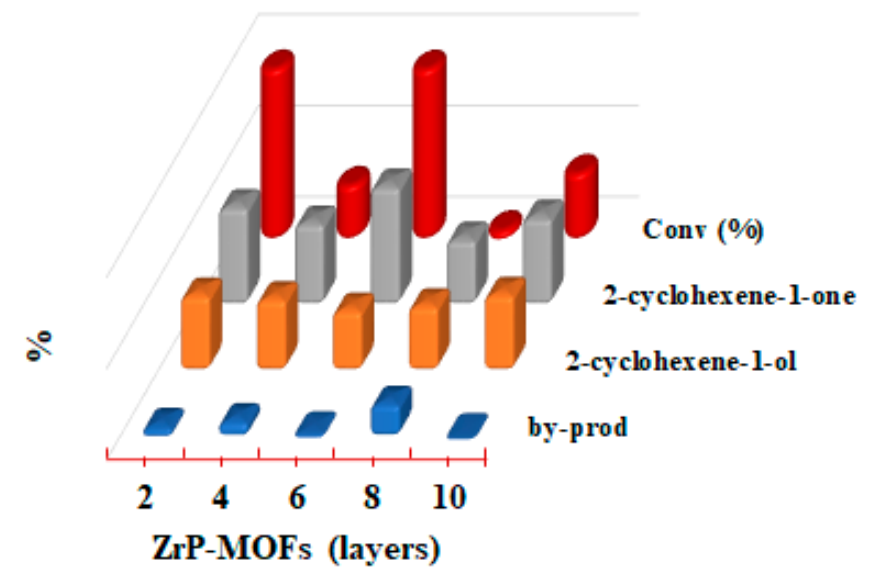

Figure 6. Conversion (\%) and product distribution (\%) with different layers of MOF-ZrP.

\section{Experimental}

\subsection{Synthesis of Zirconium Phosphate by Reflux Method}

Zirconyl chloride (10 g) was dispersed in $200 \mathrm{~mL}$ phosphoric acid solution (6 M) in a round bottom flask equipped with a condenser and a magnetic stirrer. The reaction mixture was stirred for $8 \mathrm{~h}$ at $90^{\circ} \mathrm{C}$. The product was washed with distilled water and dried in oven at $65^{\circ} \mathrm{C}$.

\subsection{Sodium Ion Exchange}

As prepared zirconium phosphate was dispersed in $0.5 \mathrm{~N}$ solution of sodium nitrate. The $\mathrm{ZrP} / \mathrm{NaNO}_{3}$ suspension was titrated against $0.1 \mathrm{~N} \mathrm{NaOH}$ and $0.1 \mathrm{~N} \mathrm{NaNO}_{3}$ solutions in 1:1 ratio with vigorous stirring. The mixture was stirred for $12 \mathrm{~h}$ when the $\mathrm{pH}$ of the reaction mixture was maintained at 8 (constant). The product (Na-ZrP) was washed with distilled water and dried in oven at $60^{\circ} \mathrm{C}$ for $24 \mathrm{~h}$.

\subsection{Synthesis of HKUST-1 on the Surface of ZrP}

$6 \mathrm{~g}$ of $\mathrm{NaZrP}$ was dispersed in $100 \mathrm{~mL}$ of ethanol in a round bottom flask. Copper acetate $(0.307 \mathrm{mg})$ solution was added to the $\mathrm{NaZrP}$ suspension and stirred for $30 \mathrm{~min}$ at $30^{\circ} \mathrm{C}$. The product was washed with ethanol several times to remove the unreacted metal precursor. The same product was again dispersed in ethanol and stoichiometric amount of trimesic acid (Benzene 1,3,5-tricarboxylic acid) was added into it and stirred for $30 \mathrm{~min}$ at $30^{\circ} \mathrm{C}$. The product (HKUST-1/ZrP) was washed with ethanol and dried. One layer of MOF (HKUST-1) deposition on the surface of NaZrP is complete. For more layers, the same process was repeated [24]. 


\subsection{Characterization of the HKUST-1/ZrP}

Scanning electron microscope (SEM) of the samples was performed by using JEOL JSM-7500F (FE-SEM). PXRD patterns were recorded with Bruker-AXS D8 short arm diffractometer. TGA was performed on a TGA Q500 TA instrument. BET surface area of the samples was determined using Micromeritics ASAP 2420 with extra pure gases. FTIR spectra were recorded with Prestige 21 Shimadzu Japan in the range $500-4000 \mathrm{~cm}^{-1}$.

\subsection{Catalytic Test of Zirconium Phosphate Supported HKUST-1}

The as prepared samples were used as a catalyst for oxidation of cyclohexene, cyclohexane and cycloheptane. Reactant(s) $10 \mathrm{~mL}$ and MOF-ZrP $(0.1 \mathrm{~g})$ were charged in a $50 \mathrm{~mL}$ three necked round bottom flask equipped with water circulator $\left(T=3^{\circ} \mathrm{C}\right)$ and magnetic stirrer. An oxygen balloon with sufficient amount of oxygen was used for oxidation. The reaction temperature was $80{ }^{\circ} \mathrm{C}$. All the reactions were carried out for $24 \mathrm{~h}$ in order to check the catalytic activity of MOF-ZrP for each substrate oxidation. Reactant and catalyst were separated from reaction mixture and sealed in air tight vials. The products were analyzed by GC-MS.

\section{Conclusions}

The surface grafted MOF was successfully synthesized via layer by layer growth of MOF on $\mathrm{ZrP}$, which shows prominent porosity, high surface area and good catalytic activity for cyclohexene oxidation. The major products for cyclohexene oxidation with oxygen at mild reaction conditions were cyclohexenol and cyclohexenone with less than one percent by products. DFT studies confirmed that the copper present on the edges of the MOF is responsible for the oxidation of cyclohexene. These active sites $\left(\mathrm{Cu}^{2+}\right)$ disappeared on dehydrating the MOF with loss of the catalytic activity for oxidation of cyclohexene. Further the increase of layers of MOF on the $\mathrm{ZrP}$ facilitate the mobility of electrons that enhances the catalytic activity of the catalyst with progressive growth of layers.

Author Contributions: R.A. carried out the research, A.C. was the PI of the project, M.S. wrote the initial draft and Z.A. performed the computational studies.

Funding: This research was funded by Zs Pharma under project \# 213510-00071.

Acknowledgments: Authors greatly acknowledge the financial support from HEC, Pakistan under IRSIP and Texas A\&M University under the project \#213510-00071, Zs Pharma. We are thankful to Hong-Cai Zhou for providing BET analysis facility. We are also thankful to Johnathan Burns, Aida Contreras and Xhuezen Wang for fruitful discussions and suggestions.

Conflicts of Interest: The authors declare no conflict of interest.

\section{References}

1. Tong, J.; Wang, W.; Su, L.; Li, Q.; Liu, F.; Ma, W.; Lei, Z.; Bo, L. Highly selective oxidation of cyclohexene to 2-cyclohexene-1-one over polyoxometalate/metal-organic framework hybrids with greatly improved performances. Catal. Sci. Technol. 2017, 7, 222-230. [CrossRef]

2. Matar, S.; Hatch, L.F. Chemistry of Petrochemical Processes, 2nd ed.; Gulf Professional Publishing: Oxford, UK, 2000; p. 60.

3. Kouw, C.B.; Li, H.X.; Dartt, C.B.; Davis, M.E. Selective Oxidation of Alkanes, Alkenes and Phenols with Aqueous $\mathrm{H}_{2} \mathrm{O}_{2}$ on Titanium Silicate Molecular Sieves. ACS Symp. Ser. 1993, 523, 273-280. [CrossRef]

4. Fu, Y.; Su, D.; Qin, M.; Huang, R.; Li, Z. Cu(II)-and Co(II)-containing metal-organic frameworks (MOFs) as catalysts for cyclohexene oxidation with oxygen under solvent-free conditions. RSC Adv. 2012, 2, 3309-3314. [CrossRef]

5. Liu, T.; Cheng, H.; Lin, W.; Zhang, C.; Yu, Y.; Zhao, F. Aerobic Catalytic Oxidation of Cyclohexene over TiZrCo Catalysts. Catalysts 2016, 6, 24. [CrossRef]

6. Cao, Y.; Yu, H.; Peng, F.; Wang, H. Selective Allylic Oxidation of Cyclohexene Catalyzed by Nitrogen Doped Carbon Nanotubes. ACS Catal. 2014, 4, 1617-1625. [CrossRef] 
7. Liu, Y.Y.; Leus, K.; Bogaerts, T.; Hemelsoet, K.; Bruneel, E.; Speybroeck, V.V.; Voort, P.V. Bimetallic-Organic Framework as a Zero-Leaching Catalyst in the Aerobic Oxidation of Cyclohexene. ChemCatChem 2013, 5, 3657-3664. [CrossRef]

8. Boudjema, S.; Rabaha, H.; Brahama, A.C. Oxidation of Cyclohexene with $\mathrm{H}_{2} \mathrm{O}_{2}$ Catalyzed by Vanadium Based Polyoxometalates Doped Modified Clays as Green Catalysts. Acta Phys. Pol. A 2017, 132. [CrossRef]

9. Junghans, U.; Kobalz, M.; Erhart, O.; PreiBler, H.; Lincke, J.; Mollmer, J.; Krautscheid, H.; Glaser, R. A Series of Robust Copper-Based Triazolyl Isophthalate MOFs: Impact of Linker Functionalization on Gas Sorption and Catalytic Activity. Materials 2017, 10, 338. [CrossRef] [PubMed]

10. Farzaneh, F.; Hamidipour, L. Mn-Metal Organic Framework as Heterogenous Catalyst for Oxidation of Alkanes and Alkenes. J. Sci. Islam. Repub. Iran 2016, 27, 31-37.

11. Yepez, R.; Garcia, S.; Schachat, P.; Sanchez, M.S.; Gonzalez-Estefan, J.H.; Gonzalez-Zamora, E.; Ibarra, I.A.; Aguillar-Pliego, J. Catalytic activity of HKUST-1 in the oxidation of trans-ferulic acid to vanillin. New J. Chem. 2015, 39, 5112-5115. [CrossRef]

12. Toyao, T.; Miyahara, K.; Fujiwaki, M.; Kim, T.H.; Dohshi, S.; Horiuchi, Y.; Matsuoka, M. Immobilization of $\mathrm{Cu}$ Complex into Zr-based MOF with Bipyridine Units for Heterogeneous Selective Oxidation. J. Phys. Chem. 2015, 119, 8131-8137. [CrossRef]

13. Toyao, T.; Styles, M.J.; Yago, T.; Sadiq, M.M.; Riccò, R.; Suzuki, K.; Horiuchi, Y.; Takahashi, M.; Matsuoka, M.; Falcaro, $\mathrm{P}$. $\mathrm{Fe}_{3} \mathrm{O}_{4} @ \mathrm{HKUST}-1$ and $\mathrm{Pd} / \mathrm{Fe}_{3} \mathrm{O}_{4} @ \mathrm{HKUST}-1$ as magnetically recyclable catalysts prepared via conversion from a Cu-based ceramic. CrystEngComm 2017, 19, 4201-4210. [CrossRef]

14. Zhao, J.; Wang, W.; Tang, H.; Ramella, D.; Luan, Y. Modification of $\mathrm{Cu}^{2+}$ into Zr-based metal-organic framework (MOF) with carboxylic units as an efficient heterogeneous catalyst for aerobic epoxidation of olefins. Mol. Catal. 2018, 456, 57-64. [CrossRef]

15. Bellezza, F.; Cipiciani, A.; Constantino, U.; Negozio, M.E. Zirconium Phosphate and Modified Zirconium Phosphates as Support of Lipase. Preparation of Composites and Activity of the Supprted Enzyme. Langmiur 2002, 18, 8737-8742. [CrossRef]

16. Stynes, J.A.; Clearfield, A. The preparation of Crystalline Zirconium Phosphate and Some Observations on Its Ion Exchange Behaviour. J. Inorg. Nucl. Chem. 1964, 26, 117-129.

17. Clearfield, A.; Duax, W.L.; Medina, A.S.; Smith, G.D.; Thomas, J.R. Mechanism of ion exchange in crystalline zirconium phosphates. I. Sodium ion exchange of alpha zirconium phosphate. J. Phys. Chem. 1969, 73, 3424-3430. [CrossRef]

18. Zhang, Y.; Xie, W.; Lu, X.; Wang, X.; Xu, S.; Lei, X. Preparation of microspherical $\alpha$-zirconium phosphate catalysts for conversion of fatty acid methyl esters to monoethanolamides. J. Colloid Interface Sci. 2010, 349, 571-577. [CrossRef] [PubMed]

19. Cheng, S.; Clearfield, A. Oxidation of ethylene catalyzed by silver supported on zirconium phosphate: Particle size and support effect. J. Catal. 1985, 94, 455-467. [CrossRef]

20. Tuteja, J.; Choudhary, H.; Nishimura, S.; Ebitani, K. Direct Synthesis of 1,6-Hexanediol from HMF over a Heterogeneous Pd/ZrP Catalyst using Formic Acid as Hydrogen Source. ChemSusChem 2014, 7, 96-100. [CrossRef] [PubMed]

21. Sinhamahapatra, A.; Sutradhar, N.; Pahari, S.K.; Pal, P.; Bajaj, H.C.; Jayachandran, M.; Panda, A.B. Allylic and Benzylic Oxidation over CrIII-Incorporated Mesoporous Zirconium Phosphate with 100\% Selectivity. Chem CatChem 2011, 3, 1447-1450. [CrossRef]

22. Khare, S.; Chokhare, R. Synthesis, characterization and catalytic activity of Fe(Salen)intercalated zirconium phosphate for the oxidation of cyclohexene. J. Mol. Catal. A Chem. 2011, 344, 83-92. [CrossRef]

23. Khare, S.; Chokhare, R. Oxidation of cyclohexene catalyzed by $\mathrm{Cu}(\mathrm{Salen})$ intercalated zirconium phosphate using dry tert-butylhydroperoxide. J. Mol. Catal. A. Chem. 2012, 353-354, 138-147. [CrossRef]

24. Kan, Y.; Clearfield, A. Zirconium Phosphate Supported MOF Nanoplatelets. Inorg. Chem. 2016, 55, 5634-5639. [CrossRef] [PubMed]

25. Blaha, P.; Schwarz, K.; Luitz, J. A Full Potential Linearized Augmented Plane Wave Package for Calculating Crystal Properties; Technical University Wien: Vienna, Austria, 2001; ISBN 3-9501031-0-4.

26. Blaha, P.; Schwarz, K.; Madsen, G.K.H.; Kvasnicka, D.; Luitz, J. WIEN2K: An Augmented Plane Wave + Local Orbital Program for Calculating Crystal Properties; Technische Universität Wien: Vienna, Austria, 2013. 
27. Perdew, J.P.; Ruzsinszky, A.; Csonka, G.I.; Vydrov, O.A.; Scuseria, G.E.; Constantin, L.A.; Zhou, X.; Burke, K. Restoring the Density-Gradient Expansion for Exchange in Solids and Surfaces. Phys. Rev. Lett. 2008, 100, 136406. [CrossRef] [PubMed]

28. Pauling, L. The Nature of the Chemical Bond, 3rd ed.; Cornell University Press: Ithaca, NY, USA, 1960.

29. Pauling, L. The Chemical Bond; Cornell University Press: Ithaca, NY, USA, 1967.

30. Mehmood, S.; Ali, Z.; Khan, I.; Ahmad, I. Effects of Cobalt Substitution on the Physical Properties of the Perovskite Strontium Ferrite. Mater. Chem. Phys. 2017, 196, 222-228. [CrossRef]

31. Jiang, D.; Mallat, T.; Meier, D.M.; Urakawa, A.; Baiker, A. Copper metal-organic framework: Structure and activity in the allylic oxidation of cyclohexene with molecular oxygen. J. Catal. 2010, 270, 26-33. [CrossRef]

(C) 2018 by the authors. Licensee MDPI, Basel, Switzerland. This article is an open access article distributed under the terms and conditions of the Creative Commons Attribution (CC BY) license (http://creativecommons.org/licenses/by/4.0/). 